\title{
Breastfeeding and common childhood diseases in Zambia: does breastfeeding have a protective effect against diarrhea, fever and acute respiratory infections among children in Zambia?
}

\author{
Chabila C. Mapoma \& Caroline Banda \\ Department of Population Studies, School of Humanities and \\ Social Sciences, University of Zambia, \\ Lusaka, Zambia \\ Email: chabilamapoma@gmail.com; \\ Christopher.mapoma@unza.zm
}

\begin{abstract}
Background: This paper aimed at answering two specific questions: does breastfeeding reduce the occurrence of ARIs, Fever and Diarrhea in children who are breastfeeding; and is the occurrence of these common childhood diseases affected by duration (period) of breastfeeding?

Data source and Method: Secondary analysis of the 2013 Zambia Demographic and Health Survey (ZDHS) was applied by using the children recode dataset (ZMKR6IFL). Analysis was done at three levels: Descriptive, bivariate and multivariate (Binary and Multinomial Logistics regressions).

Results: Results in this paper show that breastfeeding does not protect children against Diarrhea (OR I.3; I.I-I.4) but does so against Fever and ARIs (OR 0.9; 0.8-I.0). Children whose mothers were employed were more likely to suffer from all the three disease outcomes compared to those not employed (OR Diarrhea I.2; Fever I.5; ARIs I.2).

Conclusion: Diarrhea seems to be more pronounced in children who are breastfeeding than those not breastfeeding, especially those breastfed beyond 6 months.
\end{abstract}

Keywords: ARIs, Breastfeeding, Children, Diarrhea, Fever, Zambia

\section{Introduction}

Breastfeeding is highly beneficial to new born children. The long term positive effects are well documented (IHME and UNZA, 20|4). For example, 'exclusive' breastfeeding in the first six months of life has been shown to enhance children's immunity to infectious diseases; breastfeeding is also the single most effective intervention that can abate about 1315 percent infant deaths; (Tembo et al, 20I5). Other benefits of breastfeeding are long term; it improves children's Intelligent Quotient (IQ) and generally longer breastfed children have a better socioeconomic standing in society later in life (Cesar G. Victoria 2015).

Notwithstanding the importance of breast milk for infants, there exists very few studies in Zambia documenting actual prevalence of breastfeeding generally and specifically on the role breastfeeding plays in reducing or abating the occurrence of common infections such as Diarrhea, Fever and Acute Respiratory infections (ARIs).

In this article, the researcher attempts to answer two questions: Does breastfeeding reduce or contribute to the prevention of Acute Respiratory
Infection (ARI), Fever and Diarrhea in children; and secondly, does the duration (or months) of breastfeeding contribute or reduce the occurrence of these common infections in children reported currently breastfeeding? In answering these questions, the 2013 Zambia Demographic and Health Survey was used as a source of data.

In Zambia, ARIs, Fever (proxy for malaria) and Diarrhea are leading causes of childhood mortality (MCDMCH 20I3b). To establish the occurrence of ARIs, the DHS asks mothers to state whether or not their children had a cough, accompanied by short, rapid breaths or difficult breathing in the two weeks preceding the survey; in the same way mothers are asked to state whether their children had Fever or Diarrhea in the two weeks prior to the survey. Accordingly, the 20I3 ZDHS shows that 4-5 percent, 21 percent and 15 percent of children respectively suffered from ARIs, Fever and Diarrhea; and by any standard, these are significantly high proportions given their fatalities on children ( $\mathrm{MoH} 20 \mathrm{l} 2 \mathrm{~b})$.

Getting back to the problem at hand, this paper makes an attempt to investigate whether breast feeding plays a preventive role in the occurrence of http://aps.journals.ac.za 
these three common ailments' experienced in childhood; and also whether the length or duration of

\section{Literature review and theoretical framework}

Increasing the duration and exclusivity of breastfeeding could save an estimated I.5 million infant lives each year. In fact, up to 55 percent of infant deaths from diarrheal disease and acute respiratory infections may result from inappropriate feeding practices (Path adopted from UNICEF 1999). In a study by Rohmah et al (2015) in which they considered the role of breastfeeding in preventing diarrhea, the results show that there was a difference in the proportion of diarrhea between infants who were exclusively breastfed and those who were not. Exclusive breastfeeding also reduced the risk of diarrhea $(\mathrm{OR}=0.26,95 \% \mathrm{Cl} 0.08-0.83)$. Similarly, in a study conducted in the UK, Data analyzed by month of age, with adjustment for confounders, show that exclusive breastfeeding, compared with not breastfeeding, protects against hospitalization for diarrhea and lower respiratory tract infection (Quigley, 2007). breastfeeding has effects on the three common childhood diseases.

In order to assess the association between Breastfeeding and common childhood diseases in Zambia, the researcher has developed the following conceptual framework on which the analysis of this paper is based.

\section{Conceptual framework}

The framework conceptualizes how breast feeding (the main independent variable) influences three disease outcomes which are ARIs, Fever, diarrhea and a combination of all diseases. The duration of breastfeeding is of utmost importance to the analysis in this study. Therefore, months of breastfeeding have been categorized as 0-6 months, 7-24 months and 24+ months. There are background characteristics through which breastfeeding could be operating, hence an inclusion of the analysis of these variables. These include the social economic characteristics which are Mother's age, Mother's Education, Mother's employment status, household wealth and residence.

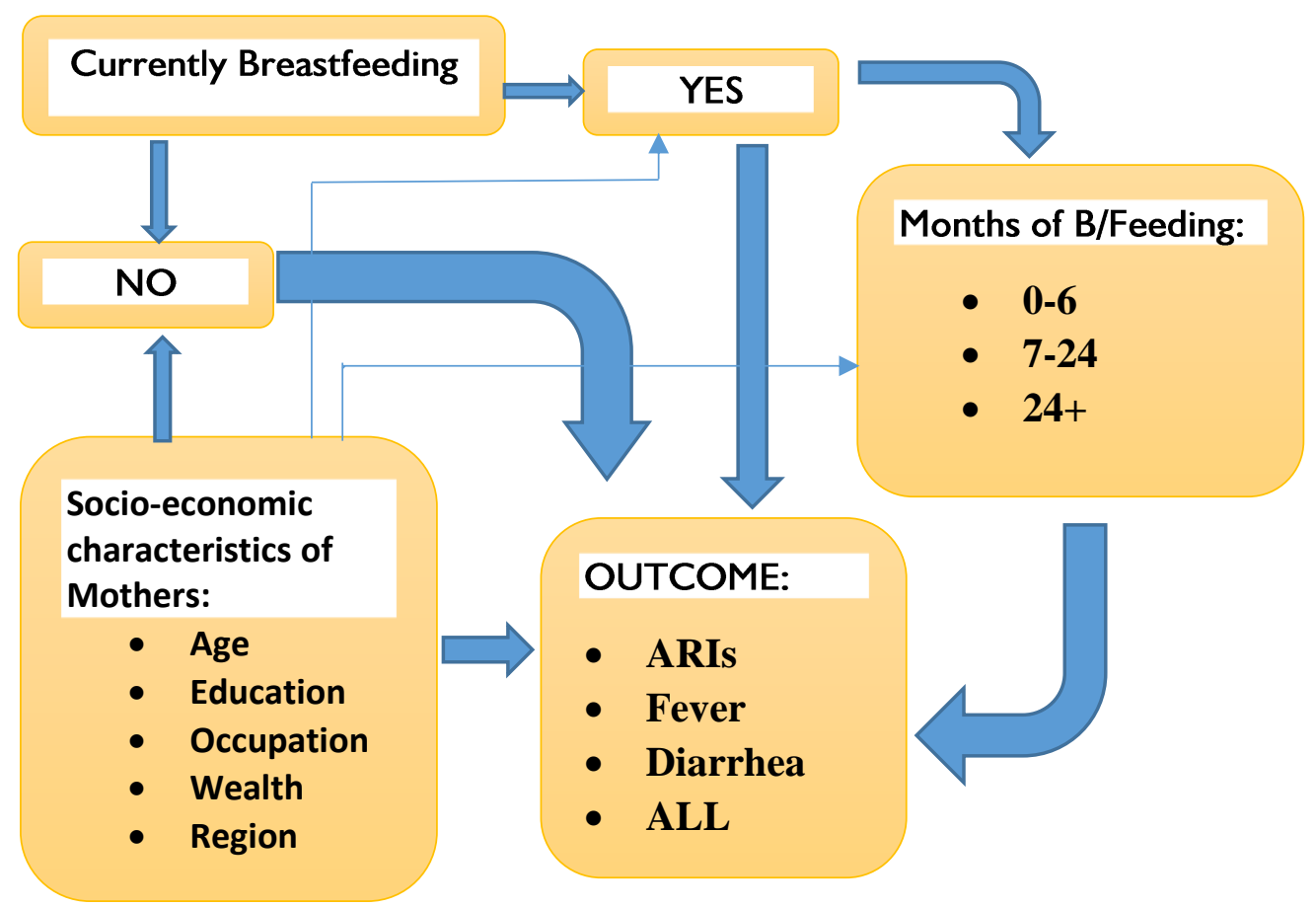

Figure I: Conceptual framework

\section{Data and methods \\ Data}

Data for this article is based on the 2013 Zambia Demographic and Health Survey (ZDHS) - children recode dataset (ZMKR6IFL) generated from the Individual Recode -Women dataset (ZMIR6IFL). The ZDHS thoroughly collects data on children, and as such is a rich resource for such data; secondly, the ZDHS is a country wide survey based on a representative sample; it produces quite accurate estimates for the entire population; and thirdly, the ZDHS reports the three diseases as problematic for children under the age of 5 years old.

A number of questions are asked to women about their breastfeeding behavior for the last three births 
they had since 2008. Two critical indicators relating to this article are important to state: a recode of question 459 (Are you breastfeeding) translating in breastfeeding. These two questions were used as predictor variables. Outcome variables on the other hand, were whether the child had ARIs, had fever or had diarrhea in the last two weeks preceding the survey.

In a general sense, the ZDHS used a two-stage cluster sampling process. In total, |6,4|| women were successfully interviewed. Records on breastfeeding, duration of breast feeding and any other data unit used in this article were based on recoded children dataset which has records of up to 13,457 children. The final sample that was used in the analysis is $11,9 \mid 4$. This is because some of the records were missing and some had a response of "I don't know" regarding if the child had ARIs, Fever or Diarrhea in the last two weeks preceding the survey. As such, these records were dropped from the analysis.

Outcome and Independent variable manipulation and analysis

The question on currently breastfeeding had a yes/no response. For both responses, bivariate analysis were performed to produce descriptive statistics. To perform bivariate analysis, the three outcome variables (if a child had ARI, diarrhea and Fever in the past two weeks preceding the survey) were each analysed independently. A follow up analysis involved inserting a logistic regression model where the three outcome variables were combined into one variable. This variable was generated by combining variables hII (if a child had diarrhea), h2I (if child had fever) and h3I (if a child had ARI). The "yes" responses to each of these variables were transformed into response "I" signifying experiencing the outcome and the "no" responses were transformed into two categories " 0 " signifying none experience of the condition (no ARIs, Fever or Diarrhea). Once this was done, socio-economic characteristics of mothers were then introduced in the model. These included mother's age, education, employment status, wealth status and residence (rural/urban). According to "currently breastfeeding" relating to the most recent birth; and a recode of $\mathrm{m} 5$ asking "number of months of breastfeeding" for those reported to be studies (Kabir et al 2017 and Maonga et al 2016) these aspects on mothers characterize breastfeeding and also give context to the occurrence of the disease outcomes of interest.

The second level of analysis was guided by the predictor "duration of breastfeeding" (in months). For those children who were being breastfed, did the length of breastfeeding influence or affect the occurrence of the three diseases under discussion in this paper? To answer this question, the variable or question in the ZDHS on "months of breastfeeding" was re-categorized to have three recommended periods of breastfeeding (IYCF Policy 2007) namely "0-6 months"; "7-24 months" and "24+ months". Outcome variables (ARIs, Diarrhea and Fever) were recoded and merged into one single variable (named "Disease") with three responses. This laid a platform to use multinomial regression. This departure was necessary so as to report the relative risk ratios and log odds of the occurrence of the outcomes by duration of breastfeeding.

\section{Results}

Sample description and prevalence of the three disease outcomes

Table I presents breastfeeding (BF) status of the child (whether they reported being breastfed at the time of the survey or not) and selected demographic and socio-economic characteristics of the mother. Over half (56 percent) of children were BF with majority (82 percent) aged between 7-24 months; most of the mothers were aged between 25-29 (26 percent), while the least number of mothers were aged 45-49 $(<2$ percent). The larger part of the sample was resident in rural areas (67 percent) while close to 3 in 5 mothers (59.I percent) were reported employed. Last but not least, close to half of mothers in the sample (47 percent) were classified as poor by Wealth Quintile (WQ) index. Generally, ARIs and Fever (23 and 22 percent respectively) were more prevalent compared to Diarrhea ( 16 percent).

Table I: Percent distribution of breastfeeding status (of child) and selected demographic and socio economic characteristics of mother

\begin{tabular}{llc}
\hline Variable & $\begin{array}{c}\text { Percent } \\
(\%)\end{array}$ & $\begin{array}{l}\text { Sample } \\
(\mathrm{N})\end{array}$ \\
\hline $\begin{array}{l}\text { Child Currently Breastfeeding } \\
\text { no }\end{array}$ & 43.7 & 5,212 \\
yes & 56.3 & 6,702 \\
\hline Months of Breastfeeding & & \\
$0-6$ months & 13 & 1,553 \\
$7-24$ months & 81.5 & 9,704 \\
4613 & & http://aps.journals.ac.za
\end{tabular}




\begin{tabular}{lll}
$24+$ months & 5.5 & 657 \\
\hline Mothers' Age (5-year groups) & 7.1 & 846 \\
$15-19$ & 23.5 & 2,805 \\
$20-24$ & 26.1 & 3,108 \\
$25-29$ & 21 & 2,501 \\
$30-34$ & 13.8 & 1,642 \\
$35-39$ & 6.9 & 821 \\
$40-44$ & 1.6 & 192 \\
$45-49$ & & \\
\hline Type of Place of Residence & 33.5 & 3,996 \\
urban & 66.5 & 7,918 \\
rural & & \\
\hline Highest Educational Level & 11 & 1,307 \\
no education & 56.3 & 6,700 \\
primary & 29.3 & 3,487 \\
secondary & 3.5 & 412 \\
higher & & \\
\hline Employment Status of Mother & 40.9 & 4,859 \\
Unemployed & 59.1 & 7,018 \\
Employed & & \\
\hline Wealth Index & 47.3 & 5,634 \\
Poor & 20.9 & 2,489 \\
Middle & 31.8 & 3,791 \\
Rich & 100 & 11,914 \\
\hline Total & &
\end{tabular}

Bivariate analysis results of breastfeeding and the three disease outcomes

Table 2 shows bivariate distribution of BF status of child and selected demographic and socio-economic characteristics of mother. From the table, more children (18 percent) who were breastfed suffered from Diarrhea compared to those who were not. However, children who were not breastfed were more likely to suffer from fever (27 percent) and ARIs (25 percent) compared to those who were being breastfed. Table 2 also shows that children whose BF period was 0-6 months were less likely to suffer from Diarrhea ( 10 percent), Fever ( 16 percent) and ARls (20 percent) compared to those whose BF period was 7-24 months and 24+ months respectively. In addition, children whose mothers were aged 15-19 were more likely, and generally so, to suffer from all the diseases of interest in this paper (23, 25 and 30 percent respectively) compared to children whose mother's ages were different (20-49 years). As for residence and education, the table shows that children in urban areas were more likely (19 percent) to suffer from Diarrhea than those in rural areas (I5 percent). However, the data also shows that children in rural areas were, on the other hand, more likely to instead suffer from Fever and
ARIs respectively compared to children in urban areas. Similarly, children whose mothers had secondary education were more likely to suffer from Diarrhea (18 percent) and ARIs (26 percent) compared to those with other education qualifications.

Results (in Table 2) also show that mother's employment status had little bearing on the occurrence of Diarrhea in children (16 percent unemployed; 17 percent employed); however, children whose mothers were employed were more likely to suffer from Fever (24 percent) and ARIs (24 percent) compared to children whose mothers were unemployed.

Table 2 also shows data on the Wealth Quintile (WQ) of mothers in relation to children experiencing the three diseases under investigation; and results show that children whose mother's WQ was classified as rich were more likely to suffer from Diarrhea (I8 percent) compared to other WQ classes; however, these children were less likely to suffer from Fever (19 percent) compared to those whose mothers WQ index was either middle (2I percent) or poor (24 percent) respectively (ZDHS, 20I3/I4). 
Table 2: Percent distribution of breastfeeding status (of child) and selected demographic and socioeconomic characteristics of mother by type of disease (diarrhea, fever and ARIs)

\begin{tabular}{|c|c|c|c|c|c|c|}
\hline & Diarrhe & & Fever & & $\begin{array}{l}\text { Acute } \\
\text { Respiratory } \\
\text { Infections }\end{array}$ & \\
\hline Variables/chi2 p-values & $\%$ & $\mathrm{Cl}$ & $\%$ & $\mathrm{Cl}$ & $\%$ & $\mathrm{Cl}$ \\
\hline \multicolumn{7}{|l|}{ Currently Breastfeeding } \\
\hline & & {$[13.5,16$} & & & & \\
\hline no & 14.7 & $\begin{array}{l}] \\
{[16.5,19 .}\end{array}$ & 22.4 & {$[20.9,24]$.} & 24.6 & {$[22.9,26]$.} \\
\hline yes & $\begin{array}{l}17.8 \\
<0.00\end{array}$ & ] & 20.7 & {$[19.4,22]$.} & 22.4 & {$[20.8,24]$.} \\
\hline $\mathrm{p}$-values & 1 & & 0.074 & & 0.033 & \\
\hline \multicolumn{7}{|l|}{ Months of Breastfeeding } \\
\hline $0-6$ months & 9.9 & ] & 15.8 & {$[13.5,18]$.} & 19.8 & {$[17.6,22]$.} \\
\hline 7-24 months & 17.8 & $\begin{array}{l}{[16.8,18]} \\
{[8.1,15.4}\end{array}$ & 22.1 & {$[20.9,23]$.} & 24.2 & {$[22.7,25]$.} \\
\hline $24+$ months & $\begin{array}{l}11.2 \\
<0.00\end{array}$ & ] & $\begin{array}{l}25.1 \\
<0.00\end{array}$ & {$[21.3,29]$.} & 20.0 & {$[16.4,24]$.} \\
\hline$p$-values & 1 & & I & & 0.001 & \\
\hline \multicolumn{7}{|l|}{ Age in 5-year Groups } \\
\hline $15-19$ & 23.2 & $\begin{array}{l}{[19.9,26 .} \\
] \\
{[16.8,20 .}\end{array}$ & 24.9 & {$[21.5,28]$.} & 30.2 & {$[26.3,34]$.} \\
\hline $20-24$ & 18.5 & ] $[14.8,18$. & 21.9 & {$[19.9,24]$.} & 24.6 & {$[22.3,27]$.} \\
\hline $25-29$ & 16.4 & ]$[12.5,15$. & 21.2 & {$[19.3,23]$.} & 23.6 & {$[21.4,26]$.} \\
\hline $30-34$ & 14.0 & ] $[12.9,18$. & 20.9 & {$[18.8,23]$.} & 22.0 & {$[19.8,24]$.} \\
\hline $35-39$ & 15.3 & ] & 21.6 & {$[19.2,24]$.} & 22.3 & {$[19.7,25]$.} \\
\hline $40-44$ & 14.0 & ] $[5.3,14.3$ & 18.8 & {$[15.6,22]$.} & 19.2 & {$[15.8,23]$.} \\
\hline $45-49$ & $\begin{array}{l}8.8 \\
<0.00\end{array}$ & ] & 21.2 & {$[15.2,28]$.} & 16.9 & {$[I I .7,23]$.} \\
\hline \multicolumn{7}{|l|}{ Type of Place of Residence } \\
\hline urban & 18.5 & $\begin{array}{l}{[16.9,20 .} \\
] \\
{[14.2,16 .}\end{array}$ & 19.2 & {$[|7.5,2|]$.} & 24.5 & {$[22.4,26]$.} \\
\hline $\begin{array}{l}\text { rural } \\
p \text {-values }\end{array}$ & $\begin{array}{l}15.4 \\
0.002\end{array}$ & ] & $\begin{array}{l}22.6 \\
0.004\end{array}$ & {$[21.2,24]$.} & $\begin{array}{l}22.8 \\
0.235\end{array}$ & {$[21.1,24]$.} \\
\hline \multicolumn{6}{|l|}{ Highest Educational Level } & \\
\hline no education & 16.0 & ]$[14.9,17$ & 24.3 & {$[21.5,27]$.} & 22.8 & {$[19.8,26]$.} \\
\hline primary & 16.0 & ] $[15.9,19$. & 21.6 & {$[20.3,23]$.} & 22.5 & {$[20.8,24]$.} \\
\hline secondary & 17.6 & ] & 20.8 & {$[19.2,22]$.} & 25.5 & {$[23.5,27]$.} \\
\hline $\begin{array}{l}\text { higher } \\
\text { p-values }\end{array}$ & $\begin{array}{l}14.2 \\
0.308\end{array}$ & ] & $\begin{array}{l}15.4 \\
0.016\end{array}$ & {$[\mid I .5,20]$.} & $\begin{array}{l}21.1 \\
0.077\end{array}$ & {$[16.5,26]$.} \\
\hline $\begin{array}{l}\text { Employment Status } \\
\text { Mother }\end{array}$ & of & & & & & \\
\hline 4615 & & & & & http://aps.jou & \\
\hline
\end{tabular}




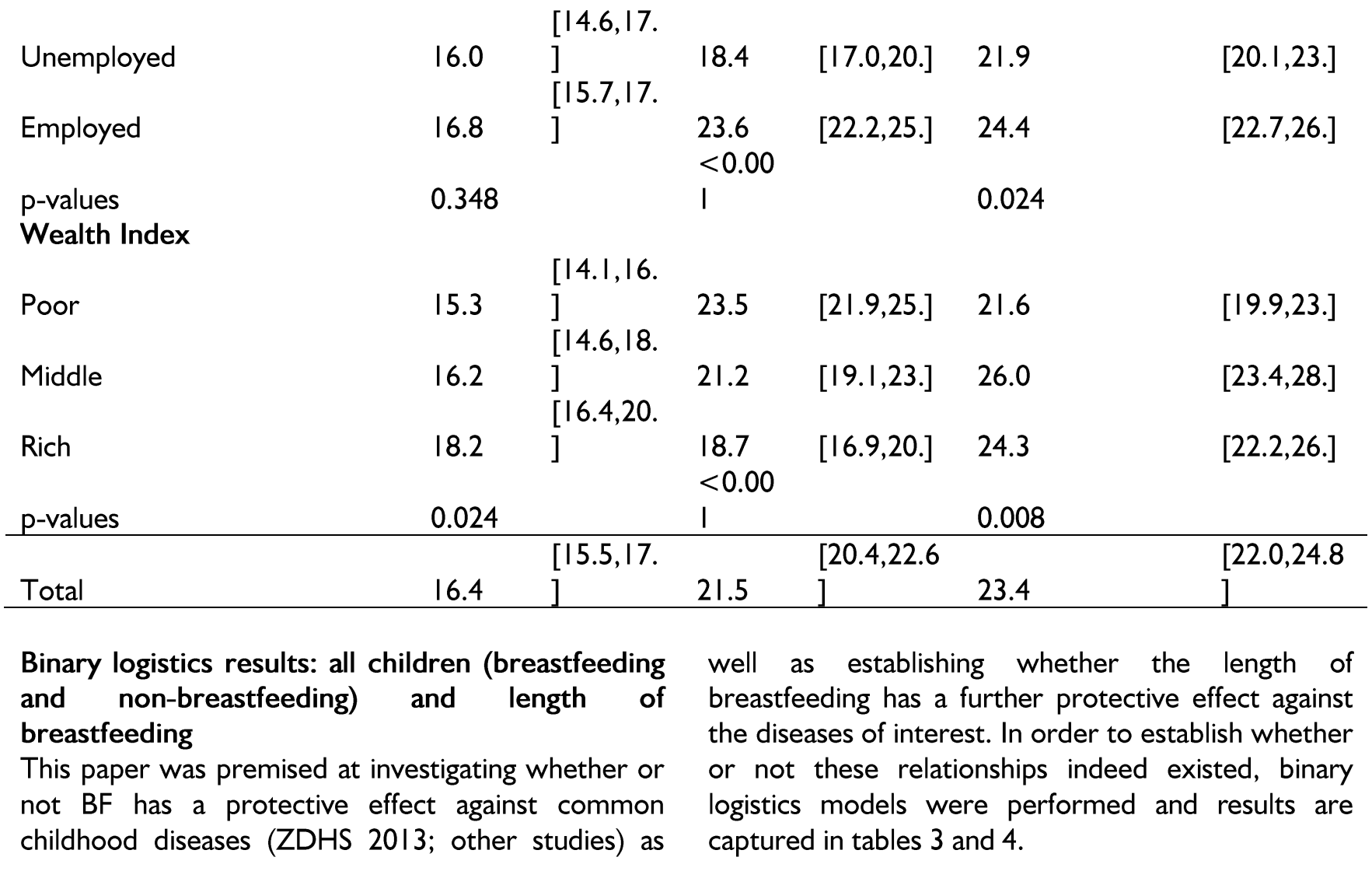

Table 3: Regression results on breastfeeding status (of child) by type of disease suffered (reported)

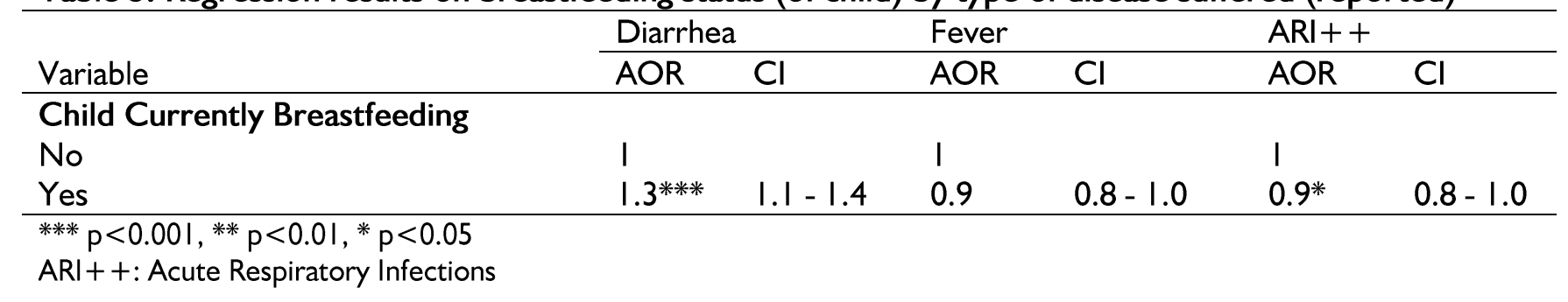

Table 4: Unadjusted and adjusted regression results on selected demographic and socio-economic characteristics of mother by type of disease suffered (reported)

\begin{tabular}{|c|c|c|c|c|c|c|}
\hline \multirow[b]{3}{*}{ Variable } & \multicolumn{2}{|c|}{ Model I } & \multicolumn{2}{|c|}{ Model 2} & \multicolumn{2}{|c|}{ Model 3} \\
\hline & \multicolumn{2}{|c|}{ Diarrhea } & \multicolumn{2}{|l|}{ Fever } & \multicolumn{2}{|l|}{ ARI++ } \\
\hline & OR & $\mathrm{Cl}$ & OR & $\mathrm{Cl}$ & OR & $\mathrm{Cl}$ \\
\hline \multicolumn{7}{|c|}{ Months of Breastfeeding } \\
\hline 7-24 months & $1.9 * * *$ & $1.6-2.5$ & $1.5 * * *$ & $1.3-1.8$ & 1.3** & $1.1-1.5$ \\
\hline \multirow[t]{2}{*}{$24+$ months } & 1.2 & $0.8-1.8$ & $1.8 * * *$ & I.4-2.4 & 1.0 & $0.8-1.3$ \\
\hline & AOR & $\mathrm{Cl}$ & AOR & $\mathrm{Cl}$ & AOR & $\mathrm{Cl}$ \\
\hline \multicolumn{7}{|c|}{ Months of Breastfeeding } \\
\hline $0-6$ months & $\mathrm{I}$ & & $\mathrm{I}$ & & $\mathrm{I}$ & \\
\hline 7-24 months & $2.8 * * * *$ & $2.2-3.6$ & $1.6 * * * *$ & $1.3-2.0$ & I.3*** & $1.1-1.6$ \\
\hline $24+$ months & $2.1^{* *}$ & $1.3-3.3$ & $1.8^{* *}$ & $1.3-2.5$ & 1.2 & $0.8-1.7$ \\
\hline \multicolumn{7}{|c|}{ Mothers' Age (5-year groups) } \\
\hline $15-19$ & I & & & & & \\
\hline $20-24$ & $0.7^{*}$ & $0.5-0.9$ & 0.8 & $0.6-1.0$ & $0.7^{*}$ & $0.5-0.9$ \\
\hline $25-29$ & $0.6 * * *$ & $0.4-0.7$ & 0.8 & $0.6-1.0$ & $0.7^{* * *}$ & $0.5-0.9$ \\
\hline $30-34$ & $0.4^{* * *}$ & $0.3-0.6$ & $0.7^{*}$ & $0.5-0.9$ & $0.6 * * *$ & $0.4-0.8$ \\
\hline $35-39$ & $0.6 * *$ & $0.4-0.8$ & $0.6 * *$ & $0.5-0.9$ & $0.6 * * *$ & $0.4-0.8$ \\
\hline http://aps.journals.ac.za & & & & & & 4616 \\
\hline
\end{tabular}


Type of Place of Residence

1 urban

rural

Highest Educational Level

1

no education

0.9

$0.7-1.1$

1.0

$0.8-1.3 \quad 1.0$

$0.8-1.2$ 1

primary

secondary

higher

Employment Status of Mother

0.9

0.9

$0.7-1.1$

0.7

$0.7-1.2$

0.9

0.9

$0.7-1.1$

0.8

$0.6-1.1$

$0.4-1.2$

0.6

$0.7-1.2$

0.8

$0.6-1.0$

$0.3-1.1 \quad 0.6$

$0.3-1.1$

Unemployed

Employed

I

Wealth Index

I.2*

I.0 - I.4

1

Poor

Middle

1

Rich

1.2

$1.0-1.4$

1.0

$1.2 *$

$1.0-1.5$

1.3

$1.0-1.6$

1.0

$0.8-1.3$

1

**** $p<0.00$ I, ** $p<0.0$ I, * $p<0.05$

$\mathrm{ARI}++$ : Acute Respiratory Infections

In Table 3, results show that the odds of suffering from Diarrhea for BF children were higher (OR I.3; I.I-I.4) compared to those not breastfeeding; however, the odds of suffering from Fever and ARIs were lower for BF children compared to nonbreastfeeding children (OR 0.9; 0.8-I.0).

Table 4 shows unadjusted and adjusted Odds Ratios (OR and AOR) of the length of breastfeeding and selected demographic and socio-economic characteristics by reported diseases. Results show that the odds of suffering from Diarrhea for children whose BF period was 7-24 months were higher (OR I.9; 1.6-2.5) compared to children whose length of BF was $0-6$ months and $24+$ months respectively; however, the odds of suffering from Fever for children who were BF for at least 24 months was about (0.8) higher than those who were BF for between 0-6 months. As for the AOR, the picture for the different $\mathrm{BF}$ periods against diseases under investigation was almost the same - in that the odds of suffering the three diseases were all time higher for children whose BF period was 7-24 months and $24+$ months respectively compared to children who had been breastfed for up to 6 months.

Beginning with age of the mother, adjusted odds ratios in Table 4 show that children whose mothers age was between 15 to 19 years had higher odds of suffering from all the three diseases compared to all other ages with the lowest experience of Diarrhea being with children whose mothers' age was between 45-49 years (AOR 0.2; 0.1-0.5). By residence, Table 4 shows little or no difference between children in urban areas and rural areas in terms of experiencing the three diseases; however, there were noticeable differences after adjusting by mother's education. The odds of suffering from the three diseases were lower for children whose mothers' education was primary, secondary and higher compared to those whose education level was none. However, children whose mothers were employed had higher odds of suffering from Diarrhea (AOR I.2; I.0-I.4), Fever (AOR I.5; I.3-I.7) and ARIs (AOR I.3; I.0-I.5) compared to mothers who were unemployed; and in all these observations, relationships were statistically significant. Similarly, children whose mothers' WQ was middle and rich had higher odds of suffering from Diarrhea (AOR I.2 and 1.3 respectively) and ARIs (AOR I.5 and 1.3 respectively) compared to children whose mothers' WQ was classified as poor. Notwithstanding these observations, results in Table 4 also show that there were no differences in children suffering from Fever by mother's WQ.

Multinomial regression results for length of breastfeeding and the three disease outcomes

Table 5 shows Unadjusted and Adjusted Relative Risk Ratio (RRR; ARRR) Results for the multinomial regression in relation to the main predictor variable (Breastfeeding Duration) and Selected Demographic and Socio-economic characteristics of mother by type of disease suffered (Reported). 
Table 5: Unadjusted and adjusted RRR for duration of breastfeeding and demographic and socioeconomic characteristics by type of disease suffered

\begin{tabular}{|c|c|c|c|c|c|}
\hline \multirow[b]{2}{*}{ Variable } & \multicolumn{2}{|c|}{$\begin{array}{l}\text { Model I } \\
\text { Diarrhea }\end{array}$} & \multicolumn{2}{|c|}{$\begin{array}{l}\text { Model } 2 \\
\text { Fever }\end{array}$} & \multirow{2}{*}{$\begin{array}{l}\text { Model } 3 \\
\text { ARI++ } \\
\text { Reference }\end{array}$} \\
\hline & RRR & $95 \% \mathrm{Cl}$ & RRR & $95 \% \mathrm{Cl}$ & \\
\hline \multicolumn{6}{|l|}{ Months of Breastfeeding } \\
\hline $0-6$ months & I & & I & & \\
\hline $7-24$ months & $1.5^{*}$ & I.0-2.I & I.I & $0.8-1.5$ & \\
\hline $24+$ months & 0.8 & $0.4-1.5$ & $1.8 * *$ & $1.2-2.8$ & \\
\hline Months of Breastfeeding & ARRR & $95 \% \mathrm{Cl}$ & ARRR & $95 \% \mathrm{Cl}$ & \\
\hline $0-6$ months & I & & I & & \\
\hline $7-24$ months & $2.0 * * *$ & $1.3-2.9$ & 1.2 & $0.8-1.6$ & \\
\hline $24+$ months & 1.2 & $0.6-2.7$ & 1.6 & $0.9-2.7$ & \\
\hline \multicolumn{6}{|c|}{ Mothers' Age (5-year groups) } \\
\hline $15-19$ & I & & & & \\
\hline $20-24$ & 1.0 & $0.6-1.6$ & 1.4 & $0.9-2.1$ & \\
\hline $25-29$ & 0.8 & $0.5-1.3$ & 1.5 & $1.0-2.2$ & \\
\hline $30-34$ & 0.9 & $0.6-1.5$ & $1.6 *$ & $1.0-2.6$ & \\
\hline $35-39$ & 1.2 & $0.7-2.1$ & $1.8^{*}$ & I.I -2.9 & \\
\hline $40-44$ & $2.0^{*}$ & I.0 - 3.7 & 1.5 & $0.8-3.1$ & \\
\hline $45-49$ & 0.6 & $0.2-2.7$ & 2.2 & $0.6-7.8$ & \\
\hline \multicolumn{6}{|l|}{ Type of Place of Residence } \\
\hline urban & I & & I & & \\
\hline rural & 0.9 & $0.6-1.3$ & I.I & $0.7-1.5$ & \\
\hline \multicolumn{6}{|l|}{ Highest Educational Level } \\
\hline no education & I & & & & \\
\hline primary & 1.2 & $0.8-1.9$ & 1.0 & $0.7-1.5$ & \\
\hline secondary & 1.4 & $0.9-2.3$ & 1.4 & $1.0-2 . \mid$ & \\
\hline higher & 1.4 & $0.5-3.4$ & 1.3 & $0.5-3.3$ & \\
\hline \multicolumn{6}{|c|}{ Employment Status of Mother } \\
\hline Unemployed & I & & 1 & & \\
\hline Employed & 0.8 & $0.6-1.1$ & I.I & $0.9-1.4$ & \\
\hline \multicolumn{6}{|l|}{ Wealth Index } \\
\hline Poor & I & & I & & \\
\hline Middle & 0.8 & $0.6-1.1$ & $0.6 * *$ & $0.5-0.8$ & \\
\hline Rich & 0.8 & $0.5-1.3$ & $0.6 * *$ & $0.4-0.9$ & \\
\hline
\end{tabular}

*** $\mathrm{p}<0.00$ I, ** $\mathrm{p}<0.01,{ }^{*} \mathrm{p}<0.05$

ARI++: Acute Respiratory Infections

For the unadjusted RRR, the table shows that the risk of suffering from Diarrhea relative to ARls was higher for children aged 7-24 months (RRR I.5; I.0-2.I) compared to those aged 0-6 months and $24+$ months respectively. The risk of suffering from Fever relative to ARIs for children BF for at least 24 months was higher (RRR I.8; I.2-2.8) compared to children at 0-6 months and those breastfeeding at age 7-24 months (RRR I.I; 0.8-I.5) respectively.

Adjusting these results by selected demographic and socio-economic characteristics shows some variations. The risk of suffering from Diarrhea relative to ARIs for children aged 7-24 months and those aged $24+$ months was higher than the reference group. In the same way, although not as significant, results show that the risk of suffering from Fever relative to ARIs for children aged 7-24 months (ARRR
I.2; 0.8-I.6) and those aged 24+ months (ARRR I.6; $0.9-2.7)$ was also higher compared to the reference category.

Results by age of mother show that, except for ages 25-29, 30-34 and 45-49, the risk of children suffering from Diarrhea relative to ARls was higher than the reference group (e.g. 40-44; ARRR 2.0; I.03.7). As for Fever, ARRR indicated in Table 5 were all higher by age of mother relative to ARIs. These results were also similar by education of mother where the risk of suffering from Diarrhea and Fever relative to ARIs respectively were all higher for the Primary (Diarrhea I.2; Fever I.0), Secondary (Diarrhea I.4; Fever I.4) and Higher education levels (Diarrhea I.4; Fever 1.3) compared to the reference group of "no education".

In terms of mothers' employment status, Table 5 shows that the risk of a child suffering from Diarrhea 
relative to ARls for employed women was lower (ARRR 0.8; 0.6-I.I) compared to unemployed women. However, the risk of a child to suffer from Fever relative to ARls for employed women was slightly higher (ARRR I.I; 0.9-I.4) than for women who were unemployed. Related to employment is the WQ. Table 5 shows that the risk of a child suffering from Diarrhea and Fever relative to ARls respectively was lower for both mothers with a middle WQ status and that of the rich WQ status (Diarrhea 0.8; Fever 0.6).

\section{Discussion}

This paper was premised on investigating whether or not breastfeeding has a protective effect on children against Diarrhea, ARIs and Fever and also investigating whether there are differences in terms of protection by length of breastfeeding. On one hand, results show that BF may not be as protective to children against Diarrhea; and many aspects maybe at play. For example, hygiene and state of the breast at BF time may expose children to infections resulting in Diarrhea. Un-breastfed children on the other hand may experience less Diarrhea due also to several reasons; one such is the assertion that they may be fed on milk formulas whose feeding utensils (feeding bottle) are thoroughly sterilized, in some areas, but not so in a low resource setting where water and electricity may be scarce. These findings are however, at variance with what has been established in literature. In their paper, Lamberti et al (20II) found evidence for the protective effects of $B F$ against diarrhea incidence, prevalence and hospitalization. However, this effect maybe more prominent in children who may have been exclusively breastfed comparatively as opposed to general BF irrespective of whether it was exclusive or not. On the other hand, results in this paper show that children who were BF were less likely to suffer from both ARIs and Fever. Comparing with what has been studied before, these results agree with Ujunwa et al (2014) who found that children who were reported to have been BF had lower risks of suffering from Pnuemonia and ARls compared to those who were not.

As to whether the length of BF affects the three outcomes under investigation, results show that, in a general sense, one can conclude that the length of $B F$ affects the occurrence of Diarrhea, ARIs and Fever in children. However, BF children for the first six months (0-6) seems to have the best protection going by results in this paper. This finding is consistent with other pieces of literature; the World Health Organization states that exclusive BF reduces infant mortality due to common childhood diseases such as Diarrhea; Kramer et al (200I) highlights that children 4619 who are breastfed have a significant reduction in the risk of gastrointestinal tract infections as well as respiratory tract infections. Breastfeeding children after 6 months (7-24 months especially) seems to put children more at risk of these diseases instead. Results show that children who are breastfed for between 7-24 months have a higher probability of suffering from the three diseases compared to those who were at 0-6 months of BF. It is not clear what this may entail, however, a number of speculative explanations may suffice. For example, it is possible that at 7 months, mothers (and other caretakers) may care less for the child compared to when it is 0-6 months and therefore they get predisposed more to infections easily; or that children at this age are also introduced to other foods and maybe reacting to their environment. At this stage of child development children are more mobile and more exposed.

Breastfeeding alone may not be a significant player in abating these common childhood diseases. Results show that BF, compounded by demographic and socio-economic characteristics of mothers or households, may actually explain the occurrence of these diseases in children. From the logistics regression output (Table 4) it is clear that children born from younger mothers (15-19) were highly likely to suffer from all the three diseases compared to other age groups. This is not unusual - these are young and inexperienced, most likely poor, uneducated girls forced into motherhood by a myriad of reasons. What is striking however about these results is the observation that children whose mothers were employed were more likely to be ill of the diseases in question (Fever and ARls especially) compared to children from unemployed mothers. It is a fact that employed women depend on others (maids or unpaid relatives) to look after their children while at work. This group of individuals may not have the acumen, experience and other motherhood attribute to take care of infants appropriately. Other studies confirm these findings: Hoffman et al (1999) found that in a general sense, working mothers spend less time with their children affecting child health and other aspects associated with child growth such as bonding. However, this argument has been discounted by others as well; they state that in fact, educated working mothers tend to compensate this absence and their children grow up to be more cognitively developed than children from uneducated unemployed mothers.

\section{Conclusion and policy implications}

This study has established that breastfed children are more likely to suffer from diarrhea but not from ARIs or Fever. It has also highlighted that the most effective period of $B F$ relative to the three common 
diseases is between 0-6 months (which mostly coincides with exclusive BF). Breastfeeding children for longer than 6 months does not necessarily protect them against the three disease outcomes under investigation in this paper; in fact, going by these results, BF children beyond 6 months seems even dangerous. This is in contrast with the findings from a study on early weaning conducted by Fawzy et al (20I I). In their study, the results show that, diarrheal episodes were I.8-fold (95\% confidence interval (Cl), I.3-2.4) higher in the short compared with long breastfeeding group. It was concluded that continued breastfeeding is associated with reduced risk of diarrhea-related morbidity and mortality. Therefore, a longitudinal or indeed a cohort study may provide better results in terms of measuring long term effects of BF on children - and not in this current paper where data was based on a cross-sectional survey whose details lacks longer term measurements employed through a longitudinal or indeed a cohort study.

In order to reduce prevalence of diarrheal related morbidity in children, there is need to educate more mothers regarding feeding practices in terms of hygiene. This is especially so beyond six months where children are introduced to complimentary foods as the high prevalence could be due to lack of hygiene in the food and utensils being used. The government should work in partnership with stakeholders to improve feeding practices among children both being breastfed and those who are not.

\section{References}

C Tembo, MC Ngoma, M Maimbolwa , A Akakandelwa. 2015. Exclusive Breastfeeding Practices in Medical Journal of Zambia, Vol. 42, No. 3: I24-I 29 (20I5).

Central Statistical Office (CSO) [Zambia], Ministry of Health $(\mathrm{MOH})$ [Zambia], and ICF International. 2014. Zambia Demographic and Health Survey 2013-I4. Rockville, Maryland, USA: Central Statistical Office, Ministry of Health, and ICF International

Cesar G. Victoria et al. 2015. Association between breastfeeding and intelligence, educational attainment, and income at 30 years of age: a prospective birth cohort study from Brazil. The Lancet Volume 3, No. 4, el99-e205, April 2015

Fawzy A., Arpadi S., Kankasa C., Sinkala M., Mwiya M., Thea M. D., Aldrovandi M. G., Kuhn L.; Early Weaning Increases Diarrhea Morbidity and Mortality Among Uninfected Children Born to
HIV-infected Mothers in Zambia, The Journal of Infectious Diseases, Volume 203, Issue 9, I May 2011, Pages 1222-1230, https://doi.org/10.1093/infdis/jir019

IHME and UNZA 20I4. Assessing Impact, Improving Health Progress in Child Health Across Districts in Zambia. A REPORT OF THE MCPA PROJECT

Kabir A, Maitrot MRL (2017) Factors influencing feeding practices of extreme poor infants and young children in families of working mothers in Dhaka slums: A qualitative study. PLoS ONE I2(2): e0172119. https://doi.org/10.1371/journal.pone.0172119

Kramer S. Michael et al (200I). Promotion of breastfeeding intervention trial (PROBIT). JAMA 285 (4): $4 \mid 4$.

Krug E.G, Mercy J.A, Dahlberg L.L and Zwi A.B (2002). The World Report on Violence and Health. The Lancet, Volume 360, Issue 9339, pp 1083-1088

Laura M. Lamberti et al (20II). Breastfeeding and the risk for diarrhea morbidity and mortality. BMC Public Health II (suppl 3): 515

Maonga, A.R., Mahande, M.J., Damian, D.J. et al. Maternal Child Health J (2016) 20: 77. doi: I0.1007/s I0995-0| 5- I 805-z

Quigley M. A, Yvonne J. Kelly, Amanda Sacker. How protective is breastfeeding against diarrheal disease in infants in 1990s England? a case-control study. Arch Dis Child. 2006;9l(3):245-50.

Rohmah, Hanifah \& Hafsah, Tisnasari \& Rakhmilla, Lulu. (20I5). Role of Exclusive Breastfeeding in Preventing Diarrhea. Althea Medical Journal. 2. 78-8I. 10.I5850/amj.v2nI.436.

UNICEF. Breastfeeding: Foundation for a Healthy Future. New York: UNICEF; 1999. Available at: www.unicef.org/publications/4308.html.

Ujunwa F.A and C.T Ezeonu (20/4). Risk factors for acute respiratory tract infections in under-five children in Enugu Southeast Nigeria. Ann Med Health Science Research. Jan-Feb 4(I): 95-99

W Hoffman, Lois \& Youngblade, Lise \& Coley, Rebekah \& Sidle, Allison \& Donna, Fuligni \& Kovacs, Dumm. (1999). Mothers at Work Effects on Children's Well-being. |0.1017/CBO97805 | 162947|

WHO. 2000. Effect of breastfeeding on infant and child mortality due to infectious diseases in less developed countries: a pooled analysis. The Lancet, Volume 355, No. 9202, p45I-455, 5 February 2000 